\title{
The molecular mechanism underlying the liver mass optimization rule
}

\author{
R. Utoh ${ }^{1}$, C. Tateno ${ }^{1,2}$ \& K. Yoshizato ${ }^{1,2,3}$ \\ ${ }^{1}$ Yoshizato Project, Hiroshima Prefectural Institute of Industrial Science \\ and Technology, Japan \\ ${ }^{2}$ PhoenixBio Co., Ltd., Japan \\ ${ }^{3}$ Department of Biological Science, Hiroshima University, Japan
}

\begin{abstract}
Liver metabolizes food materials and chemicals, and delivers nutrients to every tissue of the body and, thus, is essential to life. Nature designs the architecture of the liver in a way that the activity of liver correctly meets the need of the body, being not beyond and below it. Thus, the weight of liver $\left(\mathrm{W}_{\text {liver }}\right)$ has a correlation with that of body $\left(\mathrm{W}_{\text {body }}\right)$. The ratio $\left(\mathrm{R}_{\mathrm{L} / \mathrm{B}}\right)$ of $\mathrm{W}_{\text {liver }}$ to $\mathrm{W}_{\text {body }}$ is relatively constant among adults of a given mammalian species, indicating the presence of a "liver weight optimization rule (Rule Lwo $_{\text {)". Studies of Rule }}$ wo have been undertaken as those to identify molecular signaling required for the termination of liver regeneration using partially hepatectomized rodents. Recently, we established a novel model for studying the rule, $h$-hep-mice bearing liver repopulated with human $(h)$ hepatocytes. We compared the repopulation process of the xenogenic hepatocytes in $h$-hep-mice and $r$-hep-mice, the latter being the mice with rat $(r)$ hepatocytes. $r$-Hepatocytes proliferated following Rule $\mathrm{LwO}_{\mathrm{L}}$. In contrast, $\mathrm{R}_{\mathrm{L} / \mathrm{B}}$ of $h$-hep-mice increased during repopulation and 3 times exceeded the normal mouse $\mathrm{R}_{\mathrm{L} / \mathrm{B}}$ at the end of repopulation. The results from $h$-hep-mice suggest that molecular signaling between hepatocytes and stellate cells plays a pivotal role

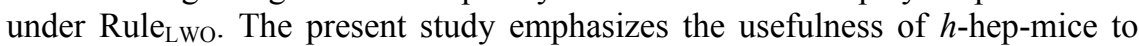

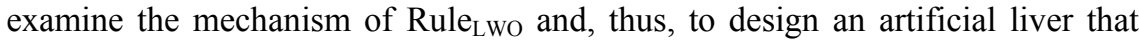
best mimics the natural liver.
\end{abstract}

Keywords: regeneration termination, organ size, allometry, termination of DNA synthesis, epithelio-mesenchymal interacting signals. 


\section{Introduction}

The liver (L) weight $\left(\mathrm{W}_{\text {liver }}\right)$ of mammals is correlated with their body (B) weight $\left(\mathrm{W}_{\text {body }}\right)$ and its ratio $\left(\mathrm{R}_{\mathrm{L} / \mathrm{B}}\right)$ is similar among adults in a species. For example, the average $\mathrm{R}_{\mathrm{L} / \mathrm{B}}(\%)$ of humans, mongrel dogs, and Fisher rats is approximately 2.5 , 2.9 , and 4.3 , respectively. Generally, there is the allometric correlation between $\mathrm{W}_{\text {liver }}$ and $\mathrm{W}_{\text {body }}$ of an adult mammal that can be described by the following equation: $\mathrm{W}_{\text {liver }}=0.33 \times \mathrm{W}_{\text {body }}{ }^{0.87}$ [1], which allows us to postulate the presence of a rule, "liver weight, or $\mathrm{R}_{\mathrm{L} / \mathrm{B}}$ optimization rule ( Rule $\left._{\mathrm{LWO}}\right)$ ".

The liver has enormous regeneration capacity throughout life. When a liver mass is lost, the hepatocytes, the parenchymal cells of the liver, in the remnant liver start to proliferate and continue the proliferation until the liver regain the original $\mathrm{R}_{\mathrm{L} / \mathrm{B}}$. Apparently, $\mathrm{R}_{\mathrm{L} / \mathrm{B}}$ is not a merely morphometric parameter, but a metabolic parameter of the body. In this article, we review the current understanding of the mechanism of regulation of $\mathrm{R}_{\mathrm{L} / \mathrm{B}}$. This mechanism has been studied as the mechanism of the termination of liver regeneration utilizing rodents that are subjected to partial (usually two third) hepatectomy (PHx) as an experimental model. We have introduced a novel mouse model for the study of Rule $_{\mathrm{LWO}}$, the mouse bearing liver composed of xenogenic hepatocytes.

\section{Rule $_{\mathrm{Lwo}}$ in the small-for-size liver transplantation}

\subsection{Human study}

Surgeons occasionally cannot help transplanting an intact liver into a recipient larger than the donor (small-for-size liver transplantation) [2]. A liver weighing $693 \mathrm{~g}$ from a 7-year-old boy whose body weight was $23 \mathrm{~kg}$ was removed as a donor liver $\left(\right.$ liver $_{\text {donor }}$ ) and orthotopically transplanted to a 44-year-woman weighing $47.5 \mathrm{~kg}$ whose liver had $1,768 \mathrm{~g}$ in weight. In this case, the original $\mathrm{R}_{\mathrm{L} / \mathrm{B}}$ of the donor and the host was 3.01 and 3.72, respectively. $\mathrm{R}_{\mathrm{L} / \mathrm{B}}$ of the host decreased from 3.72 to 1.46 just after the transplantation, which is quite smaller

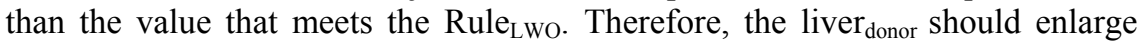
until it restores the $\mathrm{R}_{\mathrm{L} / \mathrm{B}}$ that is adequate to the host $\mathrm{W}_{\text {body. Actually, this took }}$ place by 12 days post-transplantation.

\subsection{Rat study}

A similar size-adjustment of transplanted liver to recipient body size was reported for rats [3]. Large $\left(\mathrm{W}_{\text {body }}=200-250 \mathrm{~g}\right)$ and small male Fisher rat (F-344 rats) groups $\left(\mathrm{W}_{\text {body }}=100-140 \mathrm{~g}\right)$ were utilized for the study as host and donor groups, respectively. The average $\mathrm{W}_{\text {liver }}$ of the host and donor groups was $8.99 \pm$ $1.02 \mathrm{~g}$ and $5.38 \pm 0.90 \mathrm{~g}$, respectively. When about $9 \mathrm{~g}$ livers from the large group were transplanted into the large group rats with about 9 g livers, no changes in liver weight took place. When about $5.5 \mathrm{~g}$ livers from the small group were transplanted into the large group rats with about $9 \mathrm{~g}$ livers, the liver mass increased until the organ reached the appropriate weight for the recipient. 


\subsection{Implication of studies on Rule Lwo $_{\text {I }}$}

When an optimal $\mathrm{R}_{\mathrm{L} / \mathrm{B}}$ is changed, the animal quickly "senses" the change and initiates reactions to restore the correct $\mathrm{R}_{\mathrm{L} / \mathrm{B}}$. It is conceivable that this liver size optimization is a result of biochemical reactions, which is associated with physiological conditions not only within the liver, but also outside it, because the optimization of $\mathrm{R}_{\mathrm{L} / \mathrm{B}}$ is apparently related with the need of whole body homeostasis and nutritional conditions. Considering the central roles of liver in the metabolism of nutrition, it is most probable that changes in $\mathrm{R}_{\mathrm{L} / \mathrm{B}}$ induce imbalances in homeostatis regulated by both liver and other parts of the body and, as a result, they drives the liver to remodel for restoring the optimal $\mathrm{R}_{\mathrm{L} / \mathrm{B}}$.

\section{Rule $_{\mathrm{Lwo}}$ in conventional liver regeneration animal models}

\subsection{Biological features of liver regeneration}

The liver is the center that provides materials (nutrients) for constructing and maintaining the rest of the organs and tissues. This vital demand of liver seems to be a biological reason for its remarkably high regeneration capacity through life. Liver regeneration study has been conventionally undertaken utilizing rodents, whose livers are subjected to $2 / 3 \mathrm{PHx}$. Upon loss of mass, the liver is activated, starts the regeneration business as early as $5 \mathrm{~min}$ after the loss, and reestablishes the normal weight within $5-7$ days [4].

The major event in regeneration is the recovery of number of the lost hepatocytes. The residual $1 / 3$ of hepatocytes undergoes one round of DNA synthesis with a peak at 24 hrs after the surgery of rat liver, which increase their number to $60 \%$ of the required hepatocytes. A smaller percent of the cells enter into the second round of DNA synthesis to establish the original number of hepatocytes [4]. Thus, the understanding of the signaling interactions that initiate and terminate the DNA synthesis/cell division of the hepatocytes is the most important for understanding the liver regeneration. The liver gains the original $\mathrm{R}_{\mathrm{L} / \mathrm{B}}$ during termination.

\subsection{The termination of liver generation}

Termination of regeneration is the completion of the correction of smaller $\mathrm{R}_{\mathrm{L} / \mathrm{B}}$ to the optimal $\mathrm{R}_{\mathrm{L} / \mathrm{B}}$ determined by the body weight of the host. A highly complex mechanism might underlie the termination, which includes many factors such as amounts of available nutrients and oxygen per hepatocytes. However, only a few candidates have been hitherto known as signaling molecules to terminate the regeneration. Among them two growth factors of TGF- $\beta$ superfamily, TGF- $\beta$ and activin, are considered to play prime roles as termination signals.

TGF- $\beta$, currently known as three forms, TGF- $\beta 1-3$, regulates development, growth, and homeostasis on cells of most tissues [5]. The responding cells receive its message through type I (TGF- $\beta$ RI) and type II transmembrane serine/threonine kinase receptors (TGF- $\beta$ RII), and intracellular Smad 
transduction molecules [6]. Upon TGF- $\beta$ binding, TGF- $\beta$ RII is activated, and recruits TGF- $\beta$ RI and transphosphorylates it, which enhances the TGF- $\beta$ R 1 protein kinase activity. The activated TGF- $\beta$ RI phosphorylates and activates Smad2/Smad3, and the activated Smad then bind to Smad4. The resulting Smad complex moves into the nucleus and interacts in a cell-specific manner with various transcription factors. These interactions induce up- or down-regulation of the transcription of target genes [6]. Activin A, the other member of TGF- $\beta$ superfamily, binds and stimulates activin type II receptors (ACVR2). The stimulated ACVR2 recruits ACVR1 and trans-phosphorylates it, which then recruits the Smad proteins as in TGF- $\beta$ RI [8]. The activated Smads then translocates into the nucleus where it functions as a transcription factor. Receptor-activated Smads (R-Smads) form complexes with Smad4, and translocate into the nucleus to participate in transcriptional regulation.

TGF- $\beta 1$ inhibits proliferation of cultured hepatocytes [8], most likely by suppressing synthesis of HGF [9] and by inhibiting the activation of HGF through suppressing the expression of urokinase [10]. It is currently considered that TGF- $\beta$ limits the proliferation of hepatocytes at the late phase of liver regeneration when the liver is about to regain its original $\mathrm{R}_{\mathrm{L} / \mathrm{B}}$ and stops regeneration [11]. Stellate cells are the major cells that secrete TGF- $\beta 1$ [12], strongly suggesting the requirement of coordinated interactions between hepatocytes and stellate cells to normally terminate the regeneration. Activin is also a mito-inhibitor for hepatocytes [13].

\subsection{Termination of liver regeneration in TGF- $\beta$ - and activin-gene-manipulated mice}

Studies of the gain and loss of function of gene were undertaken to test the claimed role of TGF- $\beta$ and activin as liver regeneration terminators. Transgenic mice overexpressing TGF- $\beta 1$ in the liver suppressed early DNA synthesis after $\mathrm{PHx}$, but normally terminated liver regeneration [14] against the prediction. The transgenic mice that over-expressed TGF- $\beta$ in hepatocytes regenerated almost normally despite the presence of high TGF- $\beta 1$ levels in liver and plasma [15]. Similarly, knockout (KO) mouse strains with elimination of TGF $\beta$ RII normally ended liver regeneration [16]. The cited authors created knockout mice in which TGFßRII gene (Tgf $\beta r 2)$ was liver-specifically knockouted (R2LivKO mice). R2LivKO mice showed more rapid recovery of liver mass, with a significant increase in $\mathrm{R}_{\mathrm{L} / \mathrm{B}}$ at 96 and $120 \mathrm{hrs}$ after PHx. However, there was no significant difference in liver mass between normal and R2LivKO mice at 14 days after $\mathrm{PHx}$, which indicates that termination of liver regeneration occurs normally in R2LivKO mice, despite the absence of TGF- $\beta$ signaling in the livers. It was found that activin A signaling was increased and the Smad pathway was persistently active in the regenerating R2LivKO liver. Blockage of activin A signaling by follistatin, a specific inhibitor of activin A, resulted in slightly increased hepatocyte proliferation at $120 \mathrm{hrs}$ over control animals, but there was no significant difference in $\mathrm{R}_{\mathrm{L} / \mathrm{B}}$. Therefore, there remains the possibility that neither TGF- $\beta$ nor activin is a major factor in terminating regeneration. Similar 
hepatocyte-specific $T g f \beta r 2$ KO mice, Alb-cre $T g f \beta r 2^{f l x f l x}$ mice, were created [17]. Their conclusion about the role of TGF- $\beta$ signaling in the termination of liver regeneration appeared not to be similar to that obtained with R2LivKO mice. The Alb-cre $\operatorname{Tg} f \beta r 2^{f f x f f x}$ mice increased proliferation of hepatocytes after $70 \%$ $\mathrm{PHx}$ and an increased $\mathrm{R}_{\mathrm{L} / \mathrm{B}}$ compared to the control mice, which supported the notion that TGF- $\beta$ signaling regulates the mitogenic response in the regenerating liver and affects $\mathrm{R}_{\mathrm{L} / \mathrm{B}}$.

Smad-KO mice with the following genotypes were generated [18]: C57BL/6J mice (normal control [Ctrl]); Smad2 ${ }^{+/+} \operatorname{Smad3}^{\text {dex8/dex8 }}$ (Smad3-KO, S3KO); Albcre/Smad2 $2^{\text {ff }}$ Smad3 $^{+/+}$(hepatocyte-specific Smad2-KO, S2HeKO); and Albcre/ Smad2 ${ }^{\text {fff }}$ Smad3 ${ }^{\text {dex8/dex8 }}$ (hepatocyte-specific Smad2/Smad3 double-KO, DKO). Phenotypes of DKO mice are of particular interest to our study. Both S2HeKO and DKO mice were viable. The manifested morphology, growth, and function of postnatal liver were normal for up to at least 8 months, indicating that Smad2/Smad3 was not required for liver development. Hepatocytes were isolated from $\mathrm{S} 2 \mathrm{HeKO}$ mice and were transplanted into $\mathrm{CCl}_{4}$-injured mice. The repopulation rate dramatically increased in recipient livers compared to that observed in those of the mice transplanted with hepatocytes from Ctrl mice. However, the occupancy (repopulation rate) of S2HeKO-hepatocytes was quite low ( $\sim 3 \%$ at three months post transplantation) and the data as to changes of host liver mass were not described.

Although hitherto accumulated studies strongly suggests that the signaling of TGF- $\beta$, activin, and Smad proteins plays roles in the termination of liver regeneration, these currently available "loss of function" experiments failed to directly show their expected roles.

\section{Creation of a mouse whose liver is constructed by hepatocytes of syngeneic and concordant xenogeneic animals}

\subsection{A mouse bearing liver composed of syngenic hepatocytes}

Brinster et al. created a novel mouse model of liver regeneration, an albumin promoter/enhancer-driven urokinase type plasminogen activator (uPA) gene transgenic (uPA-Tg) mouse in which hepatocyte-targeted expression of the hepatotoxic transgene (uPA gene) causes a functional liver deficit, a condition of a chronic stimulus preferable for liver growth [19]. In this mouse, when a hepatocyte stochastically deletes the deleterious transgene, it starts to replicate and selectively expands, which permits the mouse to survive beyond birth in which plasma uPA concentrations gradually return to normal by 2 months of age. Transgene-deficient cells form clonal colonies called "hepatic nodules" and eventually replace the entire liver. This study demonstrated that uPA-Tg mice will be a useful model to not only study the replicative capacity of mouse hepatocytes, but also the mechanism of liver regeneration, including the regeneration termination. 


\subsection{A mouse bearing liver composed of rat hepatocytes}

The aforementioned research group introduced the Alb-uPA transgene into immunodeficient nu/nu mice by mating uPA-Tg mice with Swiss athymic nude $(n u / n u)$ mice and generated the immunodeficient uPA-Tg mice, "uPA/nude" mice [20]. Rat liver cells were isolated from adult female Sprague-Dawley rats and were transplanted into the liver of uPA/nude mice homozygous for the transgene. The livers of $\mathrm{uPA} /$ nude mice that had not been transplanted with rat ( $r$ ) liver cells were completely pale ("white") in color. In contrast, those with $r$ liver cells were composed of white and "red" regions. The former represents the area composed of transgene-expressing host cells alone and the latter represents the area composed of transgene-deleted host [mouse $(m)$ ] cells or repopulated $r$ cells alone, or both. Immunohistochemical analysis with a mAb against $r$ hepatocytes on $\mathrm{uPA} /$ nude at $\sim 8$ weeks but, before $\sim 10$ weeks after $r$-hepatocyte transplantation when the transgene deletion had took place revealed that the red region was mostly composed of the $r$-hepatocytes. Completely regenerated transgenic mouse livers resemble normal mouse livers in color, shape, and size. The $\mathrm{R}_{\mathrm{L} / \mathrm{B}}$ of transgenic mice transplanted with $r$-liver cells is $6.8 \pm 1.0 \%$, which is similar to that of nontransgenic control mice $(5.8 \pm 0.6 \%)$. The host liver consisted of the $r$-parenchyma and the $m$-nonparenchyma including vessels, bile ducts, and associated connective tissues.

The recipient mice were clinically healthy, indicating that $r$-hepatocytes are able to not only construct the architecturally normal liver in cooperation with $m$ nonparenchymal cells beyond the species difference, but also biochemically communicate with them through signaling molecules delivered by mouse body tissues. Total serum protein and serum Alb levels in animals with rat-mouse $(\mathrm{r} / \mathrm{m}-)$ chimeric livers are similar to levels in mouse controls, which supports the notion that the synthesis of serum proteins by $r$-cells was correctly regulated by $m$-proteins. $r$-Hepatocytes are recognized as $m$-hepatocytes and supply the liver with functions of $m$-liver. Transplanted $r$-hepatocytes are able to not only normally initiate proliferation by adapting themselves to regenerative environments in the Alb-uPA-induced mouse liver and divide, replacing the transgenic parenchyma, but also seem to be able to normally terminate proliferation, because the $r / m$-chimeric livers composed of $r$-parenchyma and $m$ nonparenchyma are of similar size to mouse control livers. In other words, $r$ hepatocytes terminate the proliferation when $\mathrm{R}_{\mathrm{L} / \mathrm{B}}$ becomes optimal. Hepatocytes initiate and terminate proliferation under the influences of nonparenchymal cells. Thus, normal initiation, processing, and ending of the $r / m$-chimeric liver regeneration implies that $r$-hepatocytes produce surface proteins that are able to interact appropriately with soluble mouse-factors, $m$-extracellular matrix, and $m$ surface proteins on $m$-nonparenchymal cells.

The successful creation of a $r / m$-chimeric mouse provides a chance to consider the biological significance of $\mathrm{R}_{\mathrm{L} / \mathrm{B}}$ of mammals including an idea that a $r$-hepatocyte has an inherent mechanism to memorize the $r-\mathrm{R}_{\mathrm{L} / \mathrm{B}}$. Interesting question is "whether the $\mathrm{R}_{\mathrm{L} / \mathrm{B}}$ of $r / m$-chimeric mice is the $\mathrm{R}_{\mathrm{L} / \mathrm{B}}$ of rats or the $\mathrm{R}_{\mathrm{L} / \mathrm{B}}$ of mice. The answer is the latter, as shown below. At present, we support the 
idea that the "demands" from the rest of a mouse body regulate the gene expression associated with initiation and termination of liver regeneration in both $r$-hepatocytes and $m$-nonparenchymal cells. Therefore, it is considered that $r$ hepatocytes stop proliferation when the liver mass adequate for the mouse's body demands is acquired.

\section{Creation of a mouse whose liver is constructed by human hepatocytes}

The successful replacement of uPA/nude mouse livers with $r$-hepatocytes raised the exciting possibility that they also can be reconstituted with $h$-hepatocytes [20]. We undertook studies to generate such a mouse [21]. A severe combined immunodeficient (SCID) mouse was mated with uPA-Tg mouse to yield liverinjured SCID mice (uPA/SCID mouse). $h$-Hepatocytes were transplanted into the livers of the uPA/SCID mouse. The $h$-hepatocytes engrafted the liver at rates of as high as $92 \%$ in the best case and progressively repopulated it. Small clusters composed of 5 to $10 h$-hepatocytes were observed at 7 days after transplantation. The $h$-hepatocyte colonies gradually became larger and were almost confluent between 64 days and 81 days after transplantation, depending on individuals. The mice were able to develop livers with as high as $96 \%$ of RI. These results showed that $h$-hepatocytes are able to proliferate in $m$-liver, suggesting that the initiation signaling is normal. DNA in situ hybridization and marker proteinimmunostaining demonstrated that the mouse liver with a high RI consists of abundant $h$-hepatocytes, scant $m$-hepatocytes, $m$-nonparenchymal cells, and $m$ ECMs.

Cytochrome P450 (CYP) plays prime roles in the metabolisms of chemicals and medicines. We evaluated the functional normality of the $h$-hepatocytes in mouse liver by comparing the expression profiles of mRNAs and proteins of $h$ CYP in the chimeric mouse liver and the donor liver, and found that these expression profiles were similar [21]. We also obtained the results showing that the chimeric liver was capable of specifically responding to CYP-inducing chemicals such as rifampicin and 3-methlchoranthrene. These results indicate that $h$-hepatocytes in the mouse liver retain the specific responsiveness toward drugs as in the human liver. Thus, we conclude that $h$-hepatocytes are able to initiate regeneration in the injured mouse liver, terminate it when they largely repopulate the liver, and exhibit their normal phenotypes as to at least phenotypes that we examined.

\section{$6 \mathbf{R}_{\mathrm{L} / \mathrm{B}}$ of $\boldsymbol{h}$-hepatocytes-chimeric mice}

In the course of the study on $h / m$-chimeric mice, we noticed the size of the liver of the mice with RI $>90 \%$ was much larger than that of the normal mouse liver (manuscript in preparation), which is apparently against the Rule Lwo. We examined repopulation kinetics of $h$-hepatocytes in the uPA/SCID mouse model, using $r$-hepatocytes in the uPA/SCID mouse model as a control that completely replace the host hepatocytes following the Rule ${ }_{\text {LwO }}[20]$. Each of the $h$ - and 
$r$-hepatocytes were transplanted into the livers of uPA/SCID mouse [22]. RI of the $\mathrm{h} / \mathrm{m}$ - and $\mathrm{r} / \mathrm{m}$-mice reached $86 \%$ at 8 weeks and $100 \%$ at 5 weeks posttransplantation of $h$ - and $r$-hepatocytes, respectively. The bromodeoxyuridine (BrdU)-labeling index (Index ${ }_{\mathrm{BrdU}}$ ) in $\mathrm{r} / \mathrm{m}$ - and $\mathrm{h} / \mathrm{m}$-mice was about 15 and $9 \%$ at 1 week after transplantation, respectively, when the RI was as low as about $6 \%$ and negligible, respectively. The RI in the $r / m$-chimeric mice reached $100 \%$ at 4 weeks post-transplantation, when Index $\mathrm{BrdU}_{\mathrm{B}}$ had decreased to the control level, whereas the RI in the $h / m$ - chimeric mice was as low as $20 \%$ at 4 weeks posttransplantation when Index ${ }_{\mathrm{BrdU}}$ was still above the control level (3\%). Eleven weeks post-transplantation, the Index $\mathrm{BrdU}_{\mathrm{Br}}$ decreased to the control level and the RI was $84 \%$ in the $h / m$ - chimeric mice. These results clearly demonstrated that the repopulation kinetics of $h$-hepatocytes were quite different from those of $r$ hepatocytes. $r$-Hepatocytes rapidly proliferated and completely repopulated mouse liver by as early as 4 weeks post-transplantation, whereas $h$-hepatocytes proliferated slowly and kept proliferation for a longer period, and were not able to accomplish the complete replacement; the RI was around $90 \%$ at best even at 11 weeks post-transplantation.

The expression profiles of TGF- $\beta$ - and activin-associated signaling molecules were examined in both $h / m$ - and $\mathrm{r} / \mathrm{m}$-chimeric mice (manuscript in submission). It was noteworthy that $m$-stellate cells and $h$-hepatocytes in $h / m$-chimeric mice in the later phase of repopulation did not express TGF- $\beta$, and TGF- $\beta$ receptor and its following intracellular signaling molecules, respectively. In contrast, $m$ stellate cells and $r$-hepatocytes in $r / m$-chimeric mice normally expressed them. From these results, we currently conclude that the failure in normal intercellular communication as to liver regeneration is the cause of liver hyperplasia in $\mathrm{h} / \mathrm{m}$ chimeric mice.

\section{Conclusion-Implications of Rule $\mathrm{Lwo}_{\mathrm{O}}$ in biotechnology of liver}

Liver regeneration has been attracting researchers from viewpoints of both basic and applied sciences. Researches have been conventionally utilizing PHx rodents as an experimental animal for liver regeneration study. Relatively recently, a novel model has been put forward, a chimeric mouse bearing xenogeneic hepatocytes. In the present study, we showed the usefulness of a $h / m$-chimeric mouse for studying liver regeneration, especially for studying the mechanism of regeneration termination in relation to $\mathrm{Rule}_{\mathrm{LwO}}$, because this animal allows

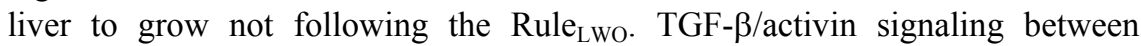
hepatocytes and stellate cells appears to be essential as functional molecules in the Rule $_{\mathrm{LWO}}$. However, the direct parameters in Rule $\mathrm{LwO}_{\mathrm{O}}$ appear to be related to nutritional imbalances caused by liver failure. There is still a big lack of knowledge between TGF- $\beta$ /activin signaling and nutritional imbalances. Our $h / m$-chimeric mouse will contribute to fill the gap. Comprehensive understanding the mechanism underlying Rule LwO $_{\text {at }}$ at the cellular and molecular levels will undoubtedly provide us an ideal type of artificial liver for liverdamaged patients that incorporates not only hepatocytes, but also 
nonparenchymal cells necessary for sensing varieties of factors involved in Rule $_{\text {Lwo. }}$

\section{References}

[1] Stahl, W.R., Organ weights in primates and other mammals. Science, 150, pp. 1039-1042, 1965.

[2] Van Thiel, D.H., Gavaler, J.S., Kam, I., Francavilla, A., Polimeno, L., Schade, R.R., Smith, J., Diven, W., Pencrot, R.J. \& Stazl, T.E., Rapid growth of an intact human liver transplanted into a recipient larger than the donor. Gastroenterology, 93, pp. 1414-1419, 1987.

[3] Francavilla, A., Zeng, Q., Polimeno, L., Carr, B.I., Sun, D., Porter, K.A., Van Thiel, D.H. \& Stazl, T.E., Small-for-size liver transplantation into large recipient: a model of hepatic regeneration. Hepatology, 19, pp. 210 216, 1994.

[4] Michalopoulos, G.K., Liver regeneration. J. Cell. Physiol., 213, pp. 286300, 2007.

[5] Roberts, A.B. \& Sporn, M.B., Peptide growth factors and their receptors. The transforming growth factors. Handbook of experimental pharmacology, Vol. 95, Part I, eds. M.B. Sporn \& A.B. Roberts, SpringerVerlag: Berlin, pp. 419-472, 1990.

[6] Shi, Y. \& Massague, J., Mechanisms of TGF- $\beta$ signaling from cell membrane to the nucleus. Cell, 113, pp. 685-700, 2003.

[7] Yasuda, H., Mine, T., Shibata, H., Eto, Y., Hasegawa, Y., Takeuchi, T., Asano, S., \& Kojima, I., Activin A: an autocrine inhibitor of initiation of DNA synthesis in rat hepatocytes. J. Clin. Invest., 92, pp. 1491-1496, 1993.

[8] Houck, K.A. \& Michalopoulos, G.K., Altered responses of regenerating hepatocytes to norepinephrine and transforming growth factor type $\beta . J$. Cell Physiol., 141, pp. 503-509, 1989.

[9] Gohda, E., Matsunaga, T., Kataoka, H. \& Yamamoto, I., TGF- $\beta$ is a potent inhibitor of hepatocyte growth factor secretion by human fibroblasts. Cell Biol. Int. Rep., 16, pp. 917-926, 1992.

[10] Mars, W.M., Kim, T.H., Stolz, D.B., Liu, M.L. \& Michalopoulos, G.K., Presence of urokinase in serum-free primary rat hepatocyte cultures and its role in activating hepatocyte growth factor. Cancer Res., 56, pp. 28372843, 1996.

[11] Fausto, N., Mead, J.E., Gruppuso, P.A. \& Braun, L., TGF- $\beta$ in liver development, regeneration, and carcinogenesis. Ann. N. Y. Acad. Sci., 593, pp. 231-242, 1990.

[12] Ikeda, H., Nagoshi, S., Ohno, A., Yanase, M., Maekawa, H. \& Fujiwara, K., Activated rat stellate cells express c-met and respond to hepatocyte growth factor to enhance transforming growth factor $\beta 1$ expression and DNA synthesis. Biochem. Biophys. Res. Commun., 250, pp. 769-775, 1998.

[13] Ho, J., de Guise, C., Kim, C., Lemay, S., Wang, X.F. \& Lebrun, J.J., Activin induces hepatocyte cell growth arrest through induction of the 
cyclin-dependent kinase inhibitor p15INK4B and Sp1. Cell Signal., 16, pp. 693-701, 2004.

[14] Bouzahzah, B., Fu, M., Iavarone, A., Factor, V.M., Thorgeirsson, S.S. \& Pestell, R.G., Transforming growth factor- $\beta 1$ recruits histone deacetylase-1 to a p130 repressor complex in transgenic mice in vivo. Cancer Res., 60, pp. 4531-4537, 2000.

[15] Sanderson, N., Factor, V., Nagy, P., Kopp, J., Kondaiah, P., Wakefield, L., Roberts, A.B., Sporn, M.B. \& Thorgeirsson. S.S., Hepatic expression of mature transforming growth factor $\beta 1$ in transgenic mice results in multiple tissue lesions. Proc. Natl. Acad. Sci. US A, 92, pp. 2572-2576, 1995.

[16] Oe, S., Lemmer, E.R., Conner, E.A., Factor, V.M., Leveen, P., Larsson, J., Karlsson, S. \& Thorgeirsson, S.S., Intact signaling by transforming growth factor $\beta$ is not required for termination of liver regeneration in mice. Hepatology, 40, pp. 1098-1105, 2004.

[17] Romero-Gallo, J., Sozmen, E.G., Chytil, A., Russell, W.E., Whitehead, R., Parks, W.T., Holdren, M.S., Her, M.F., Gautam, S., Magnuson, M., Moses, H.L. \& Grady, W.M., Inactivation of TGF- $\beta$ signaling in hepatocytes results in an increased proliferative response after partial hepatectomy. Oncogene, 24, pp. 3028-3041, 2005.

[18] Ju, W., Ogawa, A., Heyer, J., Nierhof, D., Yu, L., Kucherlapati, R., Shafritz, D.A. \& Bottinger, E.P., Deletion of Smad2 in mouse liver reveals novel functions in hepatocyte growth and differentiation. Molecular and Cellular Biology, 26, pp. 654-667, 2006.

[19] Sandgren, E.P., Palmiter, R.D., Heckel, J.L., Daugherty, C.C., Brinster, R.L. \& Degen, J.L., Complete hepatic regeneration after somatic deletion of an albumin-plasminogen activator transgene. Cell, 66, pp. 245-256, 1991.

[20] Rhim, J.A., Sandgren, E.P., Palmiter, R.D. \& Brinster, R.L., Complete reconstitution of mouse liver with xenogeneic hepatocytes. Proc. Natl. Acad. Sci. USA, 92, pp. 4942-4946, 1995.

[21] Tateno, C., Yoshizane, Y., Saito, N., Kataoka, M., Utoh, R., Yamasaki, C., Tachibana, A., Soeno, Y., Asahina, K., Hino, H., Asahara, T. Yokoi, T., Furukawa, T. \& Yoshizato, K., Near completely humanized liver in mice shows human-type metabolic responses to drugs. Am. J. Pathol., 165, pp. 901-912, 2004.

[22] Emoto, K., Tateno, C., Hino, H., Amano, H., Imaoka, Y., Asahina, K., Asahara, T. \& Yoshizato, K., Efficient in vivo xenogeneic retroviral vectormediated gene transduction into human hepatocytes. Human Gene Therapy, 16, pp. 1138-1174, 2005. 